University of Massachusetts Amherst

ScholarWorks@UMass Amherst

Chemistry Department Faculty Publication Series

Chemistry

1999

\title{
Determination of calcium, magnesium and strontium in soils by flow injection flame atomic absorption spectrometry
}

Z Arslan

JF Tyson

Follow this and additional works at: https://scholarworks.umass.edu/chem_faculty_pubs

Part of the Chemistry Commons

\section{Recommended Citation}

Arslan, $\mathrm{Z}$ and Tyson, JF, "Determination of calcium, magnesium and strontium in soils by flow injection flame atomic absorption spectrometry" (1999). TALANTA. 1052.

Retrieved from https://scholarworks.umass.edu/chem_faculty_pubs/1052 


\title{
Determination of calcium, magnesium and strontium in soils by flow injection flame atomic absorption spectrometry
}

\author{
Zikri Arslan, Julian F. Tyson* \\ Department of Chemistry, University of Massachusetts, Box 34510, Amherst, MA 01003-4510, USA
}

Received 15 March 1999; received in revised form 24 May 1999; accepted 24 May 1999

\begin{abstract}
Several procedures for the determination of $\mathrm{Ca}, \mathrm{Mg}$ and $\mathrm{Sr}$ in soils have been compared on the basis of the accuracy of analysis of two NIST reference materials (Montana Soils SRM 2710 and SRM 2711). Samples were dissolved in a mixture of hydrofluoric and nitric a cids in sealed vessels in a microwave oven and in teflon beakers on a hot plate. The digests obtained from both dissolution methods were evaporated to dryness in an attempt to remove silicon. Boric acid was added to prevent the precipitation of the lanthanum releasing agent (as lanthanum fluoride) and potassium was added as an ionization buffer. Determinations were made by flame a tomic absorption spectrometry with both the nitrous oxide-acetylene flame a nd the a ir-acetylene fl ame, wi th ca libration ei ther by standard additions or against external standards matrix matched with respect to nitric acid, boric acid, lanthanum and potassium. The silicon remaining in the solution was also determined by external calibration. A single-line flow injection manifold was used to overcome any problems due to the presence of high dissolved solids. A volume of 300 $\mu \mathrm{l}$ was injected into a water carrier stream flowing at $8 \mathrm{ml} \mathrm{min}{ }^{-1}$. To determine $\mathrm{Ca}$ in the air-acetylene flame, it was necessary to remove silicon. Magnesium was determined in either flame without complete $r$ emoval of $t$ he silicon, however, for the determination of $\mathrm{Sr}$, it was necessary to remove the silicon and use the nitrous oxide-acetylene flame. The indicative value for Sr in SRM 2710 was too low: the value determined was $360 \pm 30 \mu \mathrm{g} \mathrm{g}^{-1}$.
\end{abstract}

Keywords: Calcium; Magnesium; Strontium determination; Soil dissolution; Silicon removal; Flow injection; Flame atomic absorption spectrometry

\section{Introduction}

As part of an on-going study of the uptake of elements by marine phytoplankton, it has been

\footnotetext{
* Corresponding author. Tel.: + 1-413-545 0195; fax: + 1413-545-4846.

E-mail address: tyson@chem.umass.edu (J.F. Tyson)
}

necessary to devise validated methods for the determination of major and minor components by a number of different procedures. Although the main emphasis of our study has been on the use of plasma source mass spectrometry, methods involving flame atomic absorption spectrometry, and gas chromatography (following derivatization) with microwave induced plasma atomic 
emission detection are also under development. As there are, at present, no standard reference marine plankton materials available, suitable alternative materials for use in the method validation have been sought. We considered that soil would be a suitable surrogate reference material in this study as, to a first approximation, phytoplankton consist of a silicate skeleton together with plant-like organic material. Part of the study of plankton concerns whether it is necessary to dissolve the skeletal material to obtain information on the total elemental composition or whether an acid leaching procedure would be satisfactory. Initial experiments were conducted, in which the total elements (selected as those which could be readily determined by flame atomic absorption spectrometry) were determined following complete dissolution.

A critical stage in silicate analysis is the complete dissolution of siliceous materials. The conventional methods used are based on attacking the material with strong oxidizing acids or the use of fusion methods. The use of acids has advantages compared with fusion methods since it not only provides lower concentrations of dissolved salts, but also allows the removal of silicon by volatilization as fluoride [1]. Various workers have described methods for the complete dissolution of silicates using hydrofluoric/perchloric/nitric acids [2,5-7] hydrofluoric/sulphuric/nitric acids [2] and hydrofluoric/hydrochloric/nitric acids $[2-4,6,8]$ in polytetrafluoroethylene (PTFE)-lined pressure vessels. However, great care must be taken if perchloric acid is used due to the risk of explosion.

Although atomic absorption spectrometry is practically free from spectral interferences, chemical interferences have to be taken into account in the development of new methods. The effect of chemical interferences and the steps needed to avoid or to compensate for, these effects have been well studied in flame atomic absorption spectrometry (FAAS). Silicon, aluminum and phosphate suppress the absorption signals of calcium, magnesium and strontium in the air-acetylene flame through the formation of stable compounds. These effects can be reduced by the addition of releasing agents such as lanthanum or vanadium [4,7]. However, the addition of lanthanum to sample solutions containing fluoride results in the precipitation of lanthanum fluoride. Therefore, it is necessary to complex the excess hydrofluoric acid with boric acid prior to the addition of lanthanum [4,6,8]. However, it has been reported that for the determination of calcium by FAAS, it was necessary to use the nitrous oxide-acetylene flame and to matrix match with respect to silicon and aluminum since the lanthanum-fluoroborate-boric acid matrix did not completely eliminate the chemical interferences of silicon and aluminum [9].

Roos and Price [4] described the determination of calcium, magnesium and strontium in cement samples. However, they used the air-acetylene flame emission technique for calcium and magnesium, and determined strontium by absorption in the nitrous oxide-acetylene flame to eliminate the chemical interferences, despite the addition of boric acid and lanthanum.

Langmyhr et al. [6] used the bomb technique for decomposition of inorganic siliceous materials, and added saturated boric acid solution to the sample solutions. The authors recommended the nitrous oxide-acetylene flame for the determination of calcium and magnesium. EDTA was first used by Adams and Passmore [7] as a chelating agent to increase the effectiveness of lanthanum as a releasing agent in the air-acetylene flame. They reported that the $\mathrm{pH}$ of the solution was critical and should be adjusted to alkaline with ammonium hydroxide before final dilution to avoid subsequent precipitation of lanthanum fluoride.

Córdoba et al. reported the determination of calcium and magnesium in cements [10], soils [11], vegetables [12] and other samples with high silica content [13] with slurry nebulization flow injection flame atomic absorption spectrometry (FIFAAS). Hydrochloric/hydrofluoric and nitric/hydrofluoric acids were used as suspension media. The major problems reported were nebulizer clogging and poor reproducibility due to the large particle size and instability of the suspensions, respectively. Thus, it was necessary to further grind the materials for approximately $30 \mathrm{~min}$ prior to preparation of slurries. A T-piece was also placed between the FI manifold and the 
nebulizer to overcome the clogging problem observed for conventional FI sample introduction. Air sucked up through the T-piece allowed the introduction of the slurries in a discrete manner to the nebulizer $[10,13]$. For the vegetable samples, a precalcination step in a muffle furnace was also performed and the slurries made from the ground ash to overcome the clogging problems [12]. Soil slurries were heated in a microwave cavity for approximately $2 \mathrm{~min}$ to promote extraction of species into the suspension medium [11]. Various reagents such as glycerol [10] and Triton $\mathrm{X}-100$ [12] were used to increase the stability of suspensions with continuous magnetic stirring during the introduction of slurries to the FI manifold.

David [14] described the determination of strontium in soils and plants by FAAS with an air-acetylene flame. An anion-exchange column was used to eliminate the interference of phosphate, and the standard additions method was used for calibration. Gutteridge et al. [15] reported a method for the determination of strontium in serum, in which strontium was coprecipitated with calcium oxalate. The precipitate was dissolved in hydrochloric acid and lanthanum was added. Recently, Lin and co-workers [16] have reported a continuous co-precipitation dissolution procedure for the determination of strontium in silicate rocks. In this method, samples were dissolved by hydrofluoric/perchloric/hydrochloric acid and followed by the co-precipitation of strontium with lead sulphate with dissolution in hot EDTA.

The advantages of flow injection sample introduction in atomic spectrometry over the conventional methods are well documented [17-21]. The major advantages can be summarized as the use of reduced sample volume without loss of sensitivity, reduced analysis time due to the high sample throughput (typically in the range of 100-120 samples $\mathrm{h}^{-1}$ ), improved precision (carrier solution is continuously introduced keeping the spray chamber saturated and the burner temperature constant). Another important advantage is the higher tolerance to the dissolved solids content, since a small volume of sample solution is introduced to the carrier stream, and the nebulizer- burner system is continuously flushed with the carrier solution, which minimizes the blockage of nebulizer orifice and burner slot, as well as transport interferences and solute volatilization interferences.

We have developed a method for the determination of calcium, magnesium and strontium in silicates, based on dissolution in a mixture of hydrofluoric and nitric acids in which the depressive effect of silicon on the subsequent FAAS analysis was removed by the volatilization of silicon as the tetrafluoride. To minimize the problems associated with the build up of salts on the burner head, sample solutions were introduced to the spectrometer by a single-line FI manifold. Two methods of dissolution were evaluated. Dissolution in PTFE beakers on a hot plate was found to be preferable to dissolution of the samples in closed vessels in a microwave field.

\section{Experimental}

\subsection{Apparatus}

All measurements were made with a PerkinElmer (Norwalk, CT, USA) Model 1100 B atomic absorption spectrometer equipped with an Epson Model LQ-850 printer. Two types of interchangeable burner heads were used, a single-slot solid titanium air-acetylene burner with $100 \mathrm{~mm}$ path length and a nitrous oxide-acetylene burner with a $50 \mathrm{~mm}$ path length. Intensitron (Perkin-Elmer) hollow cathode lamps were used for the determination of $\mathrm{Sr}$ and $\mathrm{Si}$. A multi-element $(\mathrm{Ca}, \mathrm{Mg}$ and $\mathrm{Zn}$ ) hollow-cathode lamp was used for $\mathrm{Ca}$ and $\mathrm{Mg}$. Instrumental and operational parameters are given in Table 1. For the microwave digestion of the samples a CEM (Indian Trail, NC, USA) Model MSD-81D oven providing $630 \pm 70 \mathrm{~W}$ output power at $100 \%$ power setting was used. The 12-vessel turntable drive system rotates the samples $360^{\circ}$ within the microwave field at $6 \mathrm{rpm}$. The vessel body and the cap are made of polyetherimide (Ultem), and the liner, cover and the rupture membrane are made of Teflon ${ }^{\circledR}$ perfluoralkoxy (PFA). The vent screw is constructed of PTFE. The volume of the liner is $100 \mathrm{ml}$. The 
Table 1

Instrumental parameters used for determination of $\mathrm{Ca}, \mathrm{Mg}, \mathrm{Sr}$ and $\mathrm{Si}$ by FI-FAAS

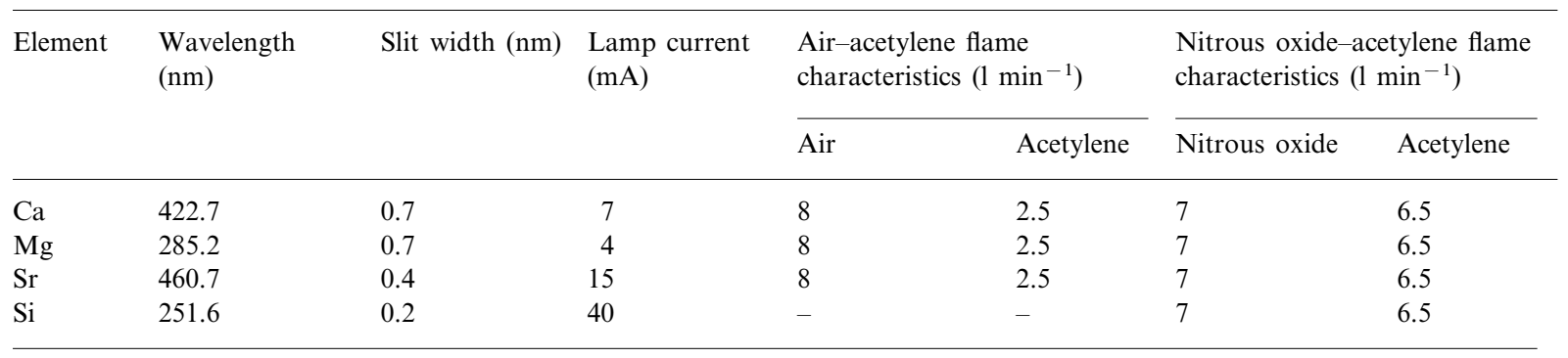

digestion power and time were adjusted from the operation control panel, and displayed during the operation. A single line flow injection manifold was used. A pump (IsmaTec sa MSREGLO) was used with Tygon pump tubes 1.5 $\mathrm{mm}$ internal diameter (i.d.) delivering a water carrier stream $8 \mathrm{ml} \min ^{-1}$. Samples were introduced by a six-port rotary flow injection valve with a $300-\mu l$ sample loop. All connecting tubing and the sample loop were made from $0.8 \mathrm{~mm}$ i.d. PTFE tubing. To minimize the dispersion, the length of tubing connecting the valve to the nebulizer was the minimum (300 $\mathrm{mm})$.

\subsection{Data collection and processing}

The peak absorbance was measured at a $10 \mathrm{~Hz}$ data collection frequency. Five replicate measurements were made. The absorbance value for each replicate was displayed on the screen of the spectrometer. After five replicates, the mean peak height absorbance, the standard deviation and the relative standard deviation (RSD) of data were calculated and displayed by the instrument, and then printed by the printer. The calibration data for each element was processed on a personal computer using a graphics software (Cricket Graph Version 1.3.2) to construct the calibration curve and to obtain the equation of the calibration curve. Visual inspection of all scatter plots indicated that the external calibration and standard additions calibration plots were linear over the concentration range used. Correlation coefficients $(r)$ ranged from 0.998 to 1.00 .

\subsection{Reagents and standard solutions}

All reagents used were of analytical grade unless specified otherwise. High-purity deionized distilled water with a resistivity of $18 \mathrm{M} \Omega \mathrm{cm}$ was used to prepare all standard and sample solutions. A boric acid stock solution $(2 \% \mathrm{~m} / \mathrm{v})$ was prepared from high purity solid boric acid (Alfa) by dissolving $5 \mathrm{~g}$ of the solid boric acid in $250 \mathrm{ml}$ of deionized water. Standard working solutions of $\mathrm{Ca}, \mathrm{Mg}, \mathrm{Sr}$ and $\mathrm{Si}$ were prepared from $1000 \mu \mathrm{g}$ $\mathrm{ml}^{-1}$ stock standard solutions by one-stage dilution with $4 \mathrm{ml}$ of concentrated $\mathrm{HNO}_{3}$ (Fisher), 30 $\mathrm{ml}$ of $2 \% \mathrm{~m} / \mathrm{v} \mathrm{H}_{3} \mathrm{BO}_{3}$ and diluting to $100 \mathrm{ml}$ with water. Lanthanum nitrate (Aldrich) and $\mathrm{KNO}_{3}$ (Fisher) were added to all standards to yield the concentrations of $0.5 \% \mathrm{~m} / \mathrm{v}$ and $1 \% \mathrm{~m} / \mathrm{v}$ for lanthanum and $\mathrm{KNO}_{3}$, respectively.

Standard and sample solutions were stored in polyethylene bottles which had been soaked in 5\% $\mathrm{v} / \mathrm{v}$ nitric acid and rinsed with water before use.

\subsection{Method development}

An alternating variable search procedure was used to investigate the effect of operating parameters and to select suitable values for these. As the variables studied were not interactive to any great extent, this procedure is satisfactory and has the advantage (over a multivariate procedure) of providing useful information about the effect of a particular parameter on the method performance.

The flow injection variables were optimized to obtain the greatest peak height sensitivity for a 5 $\mu \mathrm{g} \mathrm{ml}{ }^{-1}$ calcium standard solution. The flow rate of carrier was varied from 2 to $14 \mathrm{ml} \mathrm{min}^{-1}$. The 
volume of the sample loop was varied from 50 to $1000 \mu 1$.

For the studies of the various other parameters (reagent concentration, heating program, and calibration procedure) the figure of merit was accuracy in the analysis of the standard reference materials. The concentration of $\mathrm{KNO}_{3}$ added to standard and sample solutions as ionization suppressor was varied from 0 to $2 \% \mathrm{~m} / \mathrm{v}$. The volume of concentrated hydrofluoric acid required for complete dissolution of samples was varied from 1 to $12 \mathrm{ml}$. For dissolution of samples on a hot plate, the temperature of the hot plate was varied from 100 to $180^{\circ} \mathrm{C}$. For microwave-assisted digestion, the applied power of microwave system was varied from 20 to $60 \%$. Preliminary experiments were performed to investigate the effect of the addition of lanthanum and boric acid sequence to the sample solutions.

\subsection{Procedures}

Two different methods were used to dissolve the soil samples. One was a microwave assisted digestion (Method 1), the other involved the digestion on a hot plate in PTFE beakers (Method 2). For determination of calcium and magnesium, approximately $100 \mathrm{mg}$ of sample, $7 \mathrm{ml}$ concentrated $\mathrm{HNO}_{3}$ and $3 \mathrm{ml}$ concentrated $\mathrm{HF}$ were placed in the PTFE vessels of the microwave digestion system. The vessels were tightly capped and irradiated at $40 \%$ power for $10 \mathrm{~min}$ with continuous monitoring. At the end of the program, the vessels were removed and allowed to cool for 2-3 min in a fume hood and the pressure inside the vessels slowly released. After re-tightening, the vessels were irradiated for a further 10 min. This step was repeated three times altogether. At the end of the third time, the vessels were cooled to room temperature and opened to check if the complete dissolution, yielding colorless solutions, had been accomplished. In cases of incomplete dissolution, the microwave program was continued until the sample had dissolved. The vessels were then loosely capped and irradiated almost to dryness (30-40 min). After cooling, the residue was dissolved in $4 \mathrm{ml}$ concentrated $\mathrm{HNO}_{3}$; and diluted to $100 \mathrm{ml}$ in a calibrated flask with water after the addition of $30 \mathrm{ml}$ of $2 \% \mathrm{~m} / \mathrm{v}$ $\mathrm{H}_{3} \mathrm{BO}_{3}$, lanthanum nitrate $(0.5 \% \mathrm{~m} / \mathrm{v}$ as La) and potassium nitrate $(1 \% \mathrm{~m} / \mathrm{v})$. For the determination of strontium, approximately $150 \mathrm{mg}$ of the sample was treated with the same digestion procedure, but the final dilution was made to $50 \mathrm{ml}$ after the addition of $2 \mathrm{ml}$ of $\mathrm{HNO}_{3}$ and $15 \mathrm{ml}$ of $2 \% \mathrm{~m} / \mathrm{v} \mathrm{H}_{3} \mathrm{BO}_{3}$, lanthanum nitrate $(0.5 \% \mathrm{~m} / \mathrm{v}$ as La) and potassium nitrate $(1 \% \mathrm{~m} / \mathrm{v})$.

In Method 2, the same volumes of $\mathrm{HF}$ and $\mathrm{HNO}_{3}$ and sample masses as for Method 1 were placed in PTFE beakers. The beakers were covered with PTFE covers and heated on a hot plate at $140^{\circ} \mathrm{C}$ (measured with a mercury in glass thermometer) for 3-4 h under the fume hood. After complete dissolution, the solutions were heated at the same temperature until all acid was removed. The temperature was decreased to $70^{\circ} \mathrm{C}$ and the solid residue was heated on the hot plate for 4-5 min to remove all volatile silicon tetrafluoride. The dried samples were dissolved by warming with $4 \mathrm{ml}$ of concentrated $\mathrm{HNO}_{3}$ and the solutions were transferred to $100-\mathrm{ml}$ calibrated flasks for calcium and magnesium determinations. For strontium, $2 \mathrm{ml}$ concentrated $\mathrm{HNO}_{3}$ was added to dissolve the residue by warming, and the solution was transferred to a $50-\mathrm{ml}$ calibrated flask. Boric acid, lanthanum and potassium were added as for the Method 1.

In both digestion methods, two reagent blank solutions were also prepared with the particular digestion procedures. One was diluted to $100 \mathrm{ml}$ for $\mathrm{Ca}$ and $\mathrm{Mg}$ determinations, the other to $50 \mathrm{ml}$ for $\mathrm{Sr}$ determination. The concentrations of $\mathrm{HNO}_{3}, \mathrm{La}, \mathrm{KNO}_{3}$ and $\mathrm{H}_{3} \mathrm{BO}_{3}$ were all matched with those of the sample solutions.

The concentrations of Si remaining in the solutions after evaporation were determined, for SRM 2710 , with the nitrius oxide-acetylene flame using the optimized flow injection parameters.

\subsection{Method validation and calibration procedures}

Two NIST reference materials were used for method validation, SRM 2710 Montana Soil (Highly Elevated Traces) and SRM 2711 Montana Soil (Moderately Elevated Traces). The concentration of $\mathrm{Ca}, \mathrm{Mg}$ and $\mathrm{Sr}$ are similar in both 
samples, but only SRM 2711 is certified for the $\mathrm{Sr}$ content. All three elements were determined in the SRM 2710, whereas only $\mathrm{Sr}$ was determined in SRM 2711. Four replicate analyses were made for each SRM.

Calibration was carried out by both external and standard additions methods. For external calibration, a blank and four standards containing $4 \% \mathrm{v} / \mathrm{v} \mathrm{HNO}_{3}, 0.5 \% \mathrm{~m} / \mathrm{v} \mathrm{La}, 1 \% \mathrm{~m} / \mathrm{v} \mathrm{KNO}_{3}$ and $30 \mathrm{ml}$ of $2 \% \mathrm{~m} / \mathrm{v} \mathrm{H}_{3} \mathrm{BO}_{3}$, were used. The external standards were $0.5,1.0,2.0$ and $5.0 \mu \mathrm{g}$ $\mathrm{ml}^{-1}$ for $\mathrm{Ca}$ and $\mathrm{Sr}$, and $0.1,0.2,0.4$, and $0.6 \mu \mathrm{g}$ $\mathrm{ml}^{-1}$ for $\mathrm{Mg}$. For the determination calcium and magnesium by external calibration, original solutions were diluted 5-fold by measuring $20 \mathrm{ml}$ aliquots from the original sample solutions and diluting to $100 \mathrm{ml}$ with a solution of $4 \% \mathrm{v} / \mathrm{v}$ $\mathrm{HNO}_{3}, 0.5 \% \mathrm{~m} / \mathrm{v} \mathrm{La}, 1 \% \mathrm{~m} / \mathrm{v} \mathrm{KNO}_{3}$ and $30 \mathrm{ml}$ of $2 \% \mathrm{~m} / \mathrm{v} \quad \mathrm{H}_{3} \mathrm{BO}_{3}$. Strontium was directly determined from the original $(50 \mathrm{ml})$ solutions.

In the standard additions method, the data for one unspiked and three spiked sample solutions were used to construct the calibration curve. For the determination of $\mathrm{Ca}$ and $\mathrm{Mg}, 24 \mathrm{ml}$ portions of the five-fold diluted sample solution was transferred to a 25-ml calibrated flask by using 20-ml and 2-ml bulb pipettes. The solution was spiked with either 25,50 or $125 \mu \mathrm{l}$ of the $1000 \mu \mathrm{g} \mathrm{ml}-1$ Ca standard solution, and either 5,10 or $25 \mu 1$ of the $1000 \mu \mathrm{g} \mathrm{ml}{ }^{-1} \mathrm{Mg}$ standard solution. For the determination of $\mathrm{Sr}, 9 \mathrm{ml}$ portions of the original sample solution were transferred to a $10-\mathrm{ml}$ calibrated flask by a $10-\mathrm{ml}$ graduated pipette and spiked with either 10,20 or $50 \mu \mathrm{l}$ of $1000 \mu \mathrm{g} \mathrm{ml}-1$ $\mathrm{Sr}$ standard solution. All spiked sample solutions were then diluted to volume with a $100 \mathrm{ml}$ solution of $4 \% \mathrm{v} / \mathrm{v} \mathrm{HNO}_{3}, 0.5 \% \mathrm{~m} / \mathrm{v}$ La, $1 \% \mathrm{~m} / \mathrm{v}$ $\mathrm{KNO}_{3}$ and $30 \mathrm{ml}$ of $2 \% \mathrm{~m} / \mathrm{v} \mathrm{H}_{3} \mathrm{BO}_{3}$.

For the determination of $\mathrm{Si}$, only external calibration was performed with a blank and three aqueous standard solutions, 20, 50 and $100 \mu \mathrm{g}$ $\mathrm{ml}^{-1}$, which contained $4 \% \mathrm{v} / \mathrm{v} \mathrm{HNO}_{3}, 0.5 \% \mathrm{~m} / \mathrm{v}$ La, $1 \% \mathrm{~m} / \mathrm{v} \mathrm{KNO}_{3}$ and $30 \mathrm{ml}$ of $2 \% \mathrm{~m} / \mathrm{v} \mathrm{H}_{3} \mathrm{BO}_{3}$.

Five replicate measurements were made for each solution, and the mean peak height absorbances calculated. To calculate the concentration of each analyte, the mean peak height absorbances for the samples from the analysis solutions were substituted into the appropriate calibration equation. In the determination of the elements by the standard additions method, the concentrations of analytes were directly calculated by dividing the intercept on the absorbance axis by the slope of the calibration curve. The quotient was then corrected for the appropriate dilution factor.

\section{Results and discussions}

The optimum flow rate of the carrier stream was $8 \mathrm{ml} \mathrm{min}{ }^{-1}$. The optimum sample loop volume was $300 \mu \mathrm{l}$. For injection volumes greater than $300 \mu \mathrm{l}$, there was no significant increase in the absorbance signal compared with that for direct aspiration. The optimum concentration of $\mathrm{KNO}_{3}$ was $1 \% \mathrm{~m} / \mathrm{v}$. For the concentrations lower than $1 \% \mathrm{~m} / \mathrm{v}$, the recoveries of the analytes from the soils were significantly low due to the ionization interference which produced high absorbance values for the standards. The effect of volume of $\mathrm{HF}$ added into the digestion vessel is shown in Fig. 1 in terms of relative recoveries of $\mathrm{Ca}$ and $\mathrm{Mg}$ obtained from the $\mathrm{N}_{2} \mathrm{O}-\mathrm{C}_{2} \mathrm{H}_{2}$ and air $-\mathrm{C}_{2} \mathrm{H}_{2}$ flames, respectively. The results indicated that 1

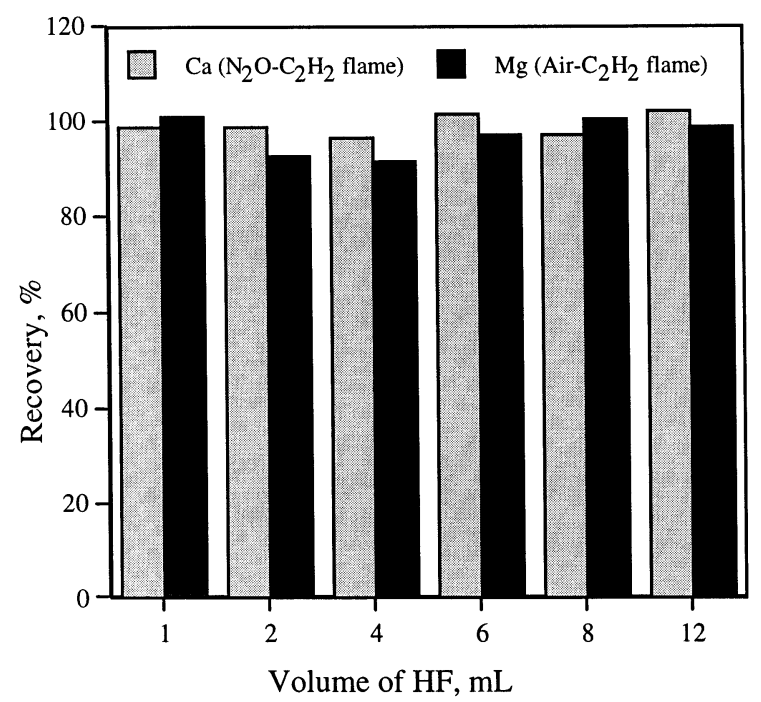

Fig. 1. The effect of concentrated hydrofluoric acid volume on the dissolution of silicate structure of soils (SRM 2710). 
Table 2

$\mathrm{Ca}, \mathrm{Mg}$ and $\mathrm{Sr}$ content of the samples solutions obtained by Method 1 in the air-acetylene and nitrous oxide-acetylene flames by FI-FAAS ${ }^{\mathrm{a}}$

\begin{tabular}{|c|c|c|c|c|c|c|}
\hline \multirow[t]{2}{*}{ Sample } & \multirow[t]{2}{*}{ Element } & \multicolumn{2}{|c|}{ Air-acetylene flame } & \multicolumn{2}{|c|}{ Nitrous oxide-acetylene flame } & \multirow[t]{2}{*}{ Certified value } \\
\hline & & $\begin{array}{l}\text { By aqueous } \\
\text { standards }\end{array}$ & $\begin{array}{l}\text { By standard } \\
\text { additions }\end{array}$ & $\begin{array}{l}\text { By aqueous } \\
\text { standards }\end{array}$ & $\begin{array}{l}\text { By standard } \\
\text { additions }\end{array}$ & \\
\hline & $\mathrm{Ca}(\%)$ & $1.01 \pm 0.05$ & $1.30 \pm 0.06$ & $1.19 \pm 0.05$ & $1.28 \pm 0.11$ & $1.25 \pm 0.03$ \\
\hline SRM 2710 & $\operatorname{Mg}(\%)$ & $0.876 \pm 0.035$ & - & $0.809 \pm 0.073$ & $0.813 \pm 0.011$ & $0.853 \pm 0.042$ \\
\hline
\end{tabular}

\footnotetext{
${ }^{\text {a }}$ Results are given as mean $\pm 95 \%$ confidence interval for four separate analyses.

${ }^{\mathrm{b}}$ Indicative value.
}

$\mathrm{ml}$ of concentrated HF was sufficient to dissolve the samples. However, $3 \mathrm{ml}$ was added to all soil samples to avoid any possible incomplete dissolution. The optimum hot plate temperature was $140^{\circ} \mathrm{C}$. At higher temperatures, distortion of the bottom of the PTFE beakers was observed. The optimum power for the microwave oven was $40 \%$, which gave a digestion time of 1-2 h. At lower power settings, not only did the digestion take longer, but did not completely dissolve some samples. A rapid increase in pressure inside the vessels occurred at higher power settings. For safety reasons, these values were not used.

A white precipitate of $\mathrm{LaF}_{3}$ was rapidly formed for method 1 solutions, when lanthanum $(0.5 \%$ $\mathrm{m} / \mathrm{v}$ ) was added prior to the $\mathrm{H}_{3} \mathrm{BO}_{3}$ solution (30 $\mathrm{ml} \mathrm{v} / \mathrm{v}$ of $2 \% \mathrm{~m} / \mathrm{v} \mathrm{H}_{3} \mathrm{BO}_{3}$ ), which did not dissolve on the addition of up to $2 \mathrm{ml}$ of concentrated $\mathrm{HNO}_{3}$. For the solutions digested by method 2, a faint turbidity was observed, indicating that some fluoride was still present, which dissolved slightly in $2 \mathrm{ml}$ of concentrated $\mathrm{HNO}_{3}$. No precipitation occurred if the boric acid solution was added prior to the lanthanum solution. Thus, the boric acid solution was added first throughout the preparation of all standard and sample solutions to avoid any possible precipitation.

The concentrations of $\mathrm{Ca}, \mathrm{Mg}$ and $\mathrm{Sr}$ obtained from the soil solutions are given in Tables 2 and 3 for methods 1 and 2, respectively. It is clear from the results of the standard additions analyses that complete dissolution of the soil samples were achieved in both digestion methods. Although the magnesium results were unaffected by the digestion method and flame conditions, those of calcium and strontium from method 1 were significantly lower than those for method 2 when the air-acetylene flame was employed. The magnesium results are in agreement with those of Oguma et al. [22], who determined magnesium (only) in silicate rock by FI-FAAS after fusion with lithium carbonate and boric acid. Interferences were overcome by the addition of lanthanum. It was thought that the depression of the calcium signals was due to the incomplete removal of silicon by method 1 . The certified concentration of silicon in SRM 2710 is $28.97 \pm 0.18 \%(\mathrm{~m} / \mathrm{m})$. Thus, the concentration of silicon would be approximately $300 \mu \mathrm{g} \mathrm{ml}^{-1}$ for $\mathrm{Ca}$ and $\mathrm{Mg}$ solutions and $900 \mu \mathrm{g} \mathrm{m}{ }^{-1}$ for $\mathrm{Sr}$ solutions if silicon was not removed by evaporation. The silicon content of the solutions from method 1 varied from 10 to $50 \mu \mathrm{g} \mathrm{ml}^{-1}$ whereas for those of method 2 it was less than $1 \mu \mathrm{g} \mathrm{ml}^{-1}$. These results indicated that for complete removal of $\mathrm{Si}$, heating to dryness is necessary. Although the majority of $\mathrm{Si}$ was also removed in Method 1 by irradiating almost to dryness, the remaining one or two drops of liquid residue at the bottom of the digestion vessel, due to the equilibrium of evaporation and condensation process, contained a significant amount of $\mathrm{Si}$. This could not be removed by evaporation to complete dryness, as for method 2, because of possible damage to the vessel body and liner by microwave radiation. The addition of lanthanum to the sample solutions did 
Table 3

$\mathrm{Ca}, \mathrm{Mg}$ and $\mathrm{Sr}$ content of the samples solutions obtained by Method 2 in the air-acetylene and nitrous oxide-acetylene flames by FI-FAAS ${ }^{\text {a }}$

\begin{tabular}{|c|c|c|c|c|c|c|}
\hline \multirow[t]{2}{*}{ Sample } & \multirow[t]{2}{*}{ Element } & \multicolumn{2}{|c|}{ Air-acetylene flame } & \multicolumn{2}{|c|}{ Nitrous oxide-acetylene flame certified } & \multirow[t]{2}{*}{ Certified value } \\
\hline & & $\begin{array}{l}\text { By aqueous } \\
\text { standards }\end{array}$ & $\begin{array}{l}\text { By standard } \\
\text { additions }\end{array}$ & $\begin{array}{l}\text { By aqueous } \\
\text { standards }\end{array}$ & $\begin{array}{l}\text { By standard } \\
\text { additions }\end{array}$ & \\
\hline \multirow[b]{2}{*}{ SRM 2710} & $\mathrm{Ca}(\%)$ & $1.29 \pm 0.03$ & $1.36 \pm 0.11$ & $1.22 \pm 0.14$ & $1.35 \pm 0.12$ & $1.25 \pm 0.03$ \\
\hline & $\operatorname{Mg}(\%)$ & $0.858 \pm 0.039$ & - & $0.856 \pm 0.065$ & $0.848 \pm 0.062$ & $0.853 \pm 0.042$ \\
\hline
\end{tabular}

\footnotetext{
${ }^{\text {a }}$ Results are given as mean $\pm 95 \%$ confidence interval for four separate analyses.

${ }^{\mathrm{b}}$ Indicative value.
}

not, therefore, completely compensate for the suppression of silicon on calcium and strontium in the air-acetylene flame. However, the suppression was eliminated by use of the hotter nitrous oxideacetylene flame.

In the case of strontium, it appears that the indicative value of $240 \mu \mathrm{g} \mathrm{g}^{-1}$ for SRM 2710 is inaccurate. It is also apparent from the results for SRM 2711 that even with the removal of silicon, inaccurate results are obtained with the airacetylene flame. However, the results of the standard additions method in the air-acetylene flame agreed with those of both external and standard additions methods in the nitrous oxide-acetylene flame. It is thought that the suppression of the $\mathrm{Sr}$ signal in the air-acetylene flame is due to the interference of other species such as aluminum and phosphate which are present at 6.44, and $6.53 \%$ for $\mathrm{Al}$ and 0.106 , and $0.086 \mu \mathrm{g} \mathrm{g}^{-1}$ for $\mathrm{P}$ in SRMs 2710 and 2711, respectively.

The slopes of the calibration curves of the standard additions methods for $\mathrm{Sr}$ in the air acetylene flame were 0.152 and 0.208 for methods 1 and 2, respectively, and they were significantly lower than that of the external method (0.239). This result also supports the hypothesis that there is a significant suppression of the $\mathrm{Sr}$ signal in the air-acetylene flame despite the removal of silicon.

The concentration of total dissolved solids in $100 \mathrm{ml}$ diluted analysis solutions was around $2 \%$ $\mathrm{m} / \mathrm{v}$ due to the addition of lanthanum $(0.5 \% \mathrm{~m} / \mathrm{v})$,
$\mathrm{KNO}_{3}(1 \% \mathrm{~m} / \mathrm{v})$ and $30 \mathrm{ml}$ of $2 \% \mathrm{~m} / \mathrm{v} \mathrm{H}_{3} \mathrm{BO}_{3}$. No blockage of nebulizer and burner was observed with the air-acetylene flame due to the flow injection introducing $300 \mu \mathrm{L}$ of $2 \% \mathrm{~m} / \mathrm{v}$ sample solutions, and analysis was performed at approximately $60-70 \mathrm{~h}^{-1}$ sampling frequency with manual injection. However, with the hotter nitrous oxide-acetylene flame, depositions were observed on the burner slot possibly due to the melting of metals and salts, which were frequently removed by a spatula to prevent the subsequent flame noise.

The absorbance data obtained from the airacetylene flame were more precise than those for the nitrous oxide-acetylene flame. The relative standard deviation (RSD) in the peak height absorbance for five replicate measurements varied in the range of $0.8-3.1 \%$ for calcium, $1.0-4.1 \%$ for magnesium, $1.2-3.6 \%$ for strontium. The major problem during the measurements with the hotter and fast-burning nitrous oxide-acetylene flame was the substantial flame noise caused by the freezing of nitrous oxide at the cylinder outlet. Although the gas supply line was electrically heated at the outlet, it was not possible to control the temperature closely. Thermostatic heating is necessary to avoid any possible change in the flame conditions. Thus, the relative standard deviation (RSD) in the peak height absorbance in the nitrous oxide-acetylene flame was significantly higher than that of the air-acetylene flame and varied from $2.5-8.5 \%$ for calcium, $2.8-7.4 \%$ for magnesium, $2.7-7.4 \%$ for strontium. 


\section{Conclusion}

It is concluded that a mixture of hydrofluoric and nitric acids can completely dissolve the silicate materials in soils without the need for perchloric or hydrochloric acids, thus minimizing reagent contamination. The calibration by standard additions method requires further treatment of the analysis solutions, which increases the total analysis time and also the risk of contamination. Thus, external calibration is recommended provided that matrix matched standard solutions are used. Calcium can be determined accurately with the nitrous oxide-acetylene flame without complete removal of silicon, while the removal of the silicon is necessary for the accurate determination in the air-acetylene flame. It is not necessary to remove the silicon to obtain accurate analyses for magnesium determination, both air-acetylene and nitrous oxide-acetylene flames can be used, but the former is twice as sensitive as the latter. Considering the problems associated with the operation and the lower precision, however, the use of fast-burning nitrous oxide-acetylene flame is not recommended for calcium or for magnesium determination. For the determination of strontium, it is concluded that the removal of silicon is not sufficient to perform accurate analysis in the air-acetylene flame despite the addition of lanthanum as a releasing agent and potassium as an ionization suppressor. Thus, the nitrous oxideacetylene flame should be used to eliminate the interferences (possibly due to aluminum and phosphates) on strontium.

It is thought that the indicative value of strontium in SRM 2710 reported by NIST is inaccurate. This hypothesis has been confirmed ${ }^{1}$.

\section{Acknowledgements}

The authors gratefully acknowledge Marmara
University (Turkey) for financial support for Zikri Arslan during the course of this study. This paper is funded in part by a grant from the National Oceanic and Atmospheric Administration (NOAA). The views expressed herein are those of the authors and do not necessarily reflect the views of NOAA or any of its sub-agencies.

\section{References}

[1] M.S. Cresser, in: N.W. Barnett (Ed.), Flame Spectrometry in Environmental Analysis. A Practical Guide, The Royal Society of Chemistry, Cambridge, 1994, pp. 62-65.

[2] C. Marqueda, J.L. Perez Rodriguez, J. Angel, Analyst 111 (1986) 1107.

[3] B. Bernas, Anal. Chem. 40 (1968) 1682.

[4] J.T.H. Roos, W.J. Price, Analyst 94 (1969) 89.

[5] C.B. Belcher, K.A. Brooks, Anal. Chim. Acta 29 (1963) 202.

[6] P.B. Adams, W.O. Passmore, Anal. Chem. 38 (1966) 630.

[7] F.J. Langmhyr, P.E. Paus, Anal. Chim. Acta 43 (1968) 397.

[8] C. Marqueda, E. Morillo, Fresenius J. Anal. Chem. 338 (1990) 253.

[9] R.W. Lee, N. Guven, Chem. Geol. 16 (1975) 53.

[10] M.A. Baustista, C.P. Sirvent, I.L. García, M.H. Córdoba, Fresenius J. Anal. Chem. 350 (1994) 359.

[11] I.L. García, M.S. Merlos, M.H. Córdoba, At. Spectrosc. 17 (1996) 107.

[12] P. Vinas, N. Campillo, I.L. García, M.H. Córdoba, Anal. Chim. Acta 283 (1993) 393.

[13] I.L. García, J.A. Cortez, M.H. Córdoba, Talanta 40 (1993) 1677.

[14] D.J. David, Analyst 87 (1962) 576.

[15] D.C. Curnow, D.H. Gutteridge, E.D. Horgan, At. Abs. Newsl. 7 (1968) 45.

[16] S. Lin, C. Zheng, H. Zu, Talanta 42 (1995) 1143.

[17] J.F. Tyson, Analyst 110 (1985) 419.

[18] J.F. Tyson, Spectrochim. Acta Rev. 14 (1991) 169.

[19] J.F. Tyson, S.R. Bysouth, E.A. Grzeszczyk, E. Debrah, Anal. Chim. Acta 261 (1992) 75.

[20] B. Welz, M. Sperling, Pure Appl. Chem. 65 (1993) 2465.

[21] Z. Fang, Flow Injection Atomic Absorption Spectrometry, Wiley, New York, 1995, pp. 45-104.

[22] K. Oguma, T. Nara, R. Kuroda, Bunseki Kagaku. 35 (1986) 690 .

\footnotetext{
${ }^{1}$ R.L. Watters, Personal Communication.
} 